\title{
AN APPROACH IN STUDYING THE EFFICIENCY OF BLENDED LEARNING SYSTEM
}

\author{
BUZADJIJA, N[evzudin] \& TIRO, D[ragi]
}

\begin{abstract}
The paper aims at demonstrating the ways in which information technologies (IT) can be used in teaching process, especially in teaching an introductory IT course (e.g. Informatics) in secondary education. One approach is to introduce blended learning system in classical and electronic forms, which would attract students' attention and increase the creative and research dimensions. This will take full effect only if all disciplines in the creation of blended learning are included and if the standards in the usage of IT and blended learning are applied, concerning infrastructure and learning objectives. We found a significant increase of the students' knowledge level and their motivation while studying in the blended learning system.

Keywords: blended learning, Claroline, e-learning, system for learning control, direction ruling, motivation and web tehnology
\end{abstract}

\section{INTRODUCTION}

The implementation of blended learning is one of the methods of applying modern information technologies used for achieving better results in secondary education. The objectives of implementing blended learning systems in studying and teaching are as it follows: improvement of learning quality, costs reduction, increase in cost effectiveness, expansion of educational accessibility and qualification, better work in bigger groups of students, acquiring the skills of using information technologies, etc. The process of introducing a blended learning system must be planned carefully and supported by government and school management. The implementation of blended learning at the level of one high school cannot succeed without support and motivation of all aimed school groups.

\section{PROBLEM DESCRIPTION}

A unique learning and teaching experience, where teachers and students use research methods combination through IT, enriches the system of collecting information in synchronized learning environment and gives a student a greater role in terms of knowledge acquisition [2].

Distributed learning environment through IT affects the satisfaction of students who attend traditional classes. The results showed that synchronized support through rich media presentations enhances students' satisfaction with online courses [6].

Combined courses can make the best use of the both ways of teaching, online and traditional. There are many advantages for teachers and students including flexibility and increased students' participation in the process of knowledge acquiring. However, it is necessary to spend a lot of time for this [3].
Effective use of online resources in blended learning will help students to achieve specific learning results. With teachers' guidance and well-designed courses, students can successfully use the relevant online resources [5].

Many researches deal with blended learning as one of the possible learning systems which is simple and complex in a way. There is a significant intuitive concept of advantage integration of synchronous and asynchronous learning in teaching activities. At the same time, there is significant complexity in its implementation as it challenges almost unlimited possibilities of composition and applicability to so many contexts.

\section{TEACHING MODELS}

Blended learning is complementary combination of elearning and traditional class. With teaching activities, the educational content enhances and the level of knowledge raises at the operational level [2]. Truly, blended learning system is only possible at the level of high school education because of students' age structure. With blended learning system, in addition to knowledge acquisition, some pedagogical and social educational activities are also necessary - which cannot be achieved with just e-learning.

Good teaching content presentation is the most important part towards the achieving minimal losses during the knowledge transfer from content to students. Therefore, every teaching model consists of the three main steps: a. introducing aims to beginners, b. presentation of information, c. practicing acquired skills.

In the area of teaching Informatics in $\mathrm{B} \& \mathrm{H}$ today, computers are used for practical curriculum realization depending on schools' IT-equipment in so-called "ITlab". In most cases, syllabi are obsolete and do not follow changes that occur in information and communication technologies (ICT). Because of a specific constitutional system imposed by Dayton Agreement (1995), there is no unique educational system in $\mathrm{B} \& \mathrm{H}$, hence, in most cases, the teachers are left to themselves and they create teaching process according to their discretion.

Estimation tests are formed in order to simulate real problems. In that way, results show real influence of user's knowledge which it will have on business performances. During knowledge check, results are associated with learning objects, and these results instruct 
students in new reviewing of those teaching units for which they didn't get good results.

\section{RESEARCH MODEL}

The research represents synthetic access to efficiency evaluation by which we connect experiment and idea about checking the system's efficiency in as bigger number of interim results as it is possible. The main aim of the experiment is to find out if there is, how big it is and what kind of influence of some specific independent variable is on the specific dependent variable. In this research, the independent variable represents the cause, i.e. teaching process, and this represents innovative models of working with students in Informatics science, formed according to experimental program. The level of achieved success is measured by the final test.

Therefore, we have formed parallel groups and we defined dependent and independent variables. Due to that, we have made our access to drawn plan easier.

Dependent variables:

1. Students' contentment by learning in Informatics science,

2. Adoption of teaching materials in Informatics,

3. Stimulating students' interest in Informatics. Independent variables:

1. Learning by using Claroline computer system,

2. Age,

3. Previous knowledge.

For the purpose of our research, we defined one variant of experimental research with parallel groups. Speaking about experiments with parallel groups, there are two groups of subjects out of which each group is a holder of its own experimental factor - the control group is taught using traditional method of learning and experimental group is taught using e-learning system.

The research should give the answers referring to possibilities of e-learning model implementation in order to improve teaching efficiency in secondary school education. The broader issue under which the research will also be done is to find out if e-learning system could be implemented on the level of secondary school education, in the way that it statistically has significant influence on the efficiency of teaching process. The narrower issue of this research should demonstrate whether e-learning system contributes to the increase of students' motivation in teaching process.

The methods of research: Descriptive method gathers information about education level in Informatics as well as about students' opinion in relation to innovative teaching process. Experiment with parallel groups is used in research. Comparative method compares the results of initial and final measuring in experimental and control groups, calculating the level of statistical significance of distinction, comparing the results of initial and final checking of knowledge in experimental groups.

The sample included in this experiment is based on the data recorded by LMS system (free software Claroline). Skills and speed of education program acquirement, created in the system with help of elearning device, are examined.

The defined hypotheses are as they follow:

H1: Students achieve better results in combined education system and automated system of testing and practicing.

H2: Students of high school can use devices for electronic education successfully from the subject Informatics with a high level of motivation.

The aim of the research is to adopt guidelines for the systematic implementation of blended learning in high schools in order to increase students' motivation. Motivation is a precondition for acquiring applied knowledge acceptable to the world market. The research is conducted since the current situation is not satisfactory in terms of students' knowledge which they acquire through the traditional education system.

\section{Sample}

The students of electrical engineering high school with two professions (electrical technician and computer technician) are examined, namely - classes: I, II and III; considering that we have two classes per each class which educate for named professions.

The study was limited to the implementation of blended learning on students aged 14-18 years in secondary schools. The study shows the effect of e-learning combined with traditional teaching on the level of students' knowledge at the end of the school year.

\begin{tabular}{|c|c|c|c|}
\hline Classes & $\begin{array}{c}\text { Students } \\
\text { number }\end{array}$ & Control group & $\begin{array}{c}\text { Experimental } \\
\text { group }\end{array}$ \\
\hline I3 & 29 & & 29 \\
\hline I4 & 29 & 29 & 31 \\
\hline II3 & 31 & & 34 \\
\hline II4 & 31 & 31 & \\
\hline III3 & 34 & & $\mathbf{9 4}$ \\
\hline III4 & 34 & 34 & \\
\hline Total & $\mathbf{1 8 8}$ & $\mathbf{9 4}$ & \\
\hline
\end{tabular}

Tab. 1. Review of students' number classified by groups

It should be noted that the control and experimental group attended classical program with the same curriculum, although the experimental group was exposed to additional way of teaching through e-learning, which they followed from their houses or internet clubs. It means that students from experimental group didn't use e-learning in school. Throughout this platform, they could take over lectures which they listened at class. After every lesson, they had exercises at LMS platform like multiple choices and addendums, while the students of control group were exposed to classical knowledge assessment. Both groups had identical test at the beginning and end of the experiment in written form.

Also, we wanted to know whether using computers and Internet can improve the level of students' knowledge and increase students' motivation to the acquirement of Informatics matter.

After surveying, we gave the previous knowledge test so to enable the question whether there is a higher deviation between two different groups concerning previous knowledge, as our aim is the equality between groups considering knowledge possession at that 
moment. This will contribute to higher reliability of results at the end of testing.

\section{RESULTS AND DISCUSSION}

According to the most successful research and according to classes' experience and results, we defined classes in advance, i.e. which group will be the experimental one and which group will be the controlling one. From the query into the documentation of classes which we have planned to test and compare, we evaluated that all grades which will be included into the research are pretty much equaled.

This survey was used to ascertain in what we assumed within the meaning of the lack of students' motivation. Besides that, throughout this survey, our aim was to remove all students' deficiencies concerning preconditions in order to start the research and form experimental and control groups. It is not the aim of this to start with the research and then start to remove deficiencies, which is the condition for the significant research, i.e. the aim of the work is to have the smallest number of mistakes which cannot affect the final testing result.

The second survey is conducted at the end of testing, i.e. after treatment's end by independent variable. Based on this survey, its aim is to accept or reject hypothesis: "Students of high school education can successfully use devices for electronic education from the subject Informatics with a high level of motivation."

Using this survey, we explored the influence of experimental factor at two dependable variables: the ability of high school students to successfully use devices of the e-learning system and influence on students' motivation.

According to the question reply: "How much time do you spend weekly in the Claroline environment?", more than $51 \%$ of the students replied that they used to spend one hour and even more. This shows us that students were interested in the meaning of additional acquirement of teaching content which they learned at ordinary classes. With annotation that they have two classes of Informatics per week, it indicates that they used more this way of learning.

According to the question: "Do you understand the content you had in the Claroline system?", $79 \%$ of them answered that they completely understood the content they had at the Claroline system. $14 \%$ of them understood it partially, and $6 \%$ of them did not understand the content.

However, even though the most of them understood the teaching content, this shows that students need to be more educated in order to use this type of learning without problems.

The values of variables are determined by polling of students in relation to their opinion about blended learning, evaluation of students' interest in compare to the control values and values achieved in tests (TPZ previous knowledge test, T1 and T2 - tests after finishing a certain thematic chapter and ZT - final test). The results of finished test in the third grades taken after conducted research are shown throughout tabular view of results and graphs based on several methods done in Statistics 8 .

\begin{tabular}{|c|c|c|c|c|c|c|c|c|}
\hline & TPZ-K & TPZ-E & T1-K & T1-E & T2-K & T2-E & ZT-K & ZT-E \\
\hline \multicolumn{9}{|c|}{ I class } \\
\hline Mean & 29,05 & 29,33 & 57,72 & 52,72 & 60,41 & 57,75 & 51,9 & 54,3 \\
\hline Variance & 140,95 & 185,67 & 272,56 & 381,05 & 214,82 & 132,34 & 116,15 & 137,35 \\
\hline Df & 28 & 28 & 28 & 28 & 28 & 28 & 28 & 28 \\
\hline Std. Dev. & 11,87 & 13,63 & 16,51 & 19,52 & 14,66 & 11,50 & 10,78 & 11,72 \\
\hline F-ratio Variances & \multicolumn{2}{|c|}{1,317} & \multicolumn{2}{|c|}{1,398} & \multicolumn{2}{|c|}{1,623} & \multicolumn{2}{|c|}{1,183} \\
\hline $\mathbf{P}$ & \multicolumn{2}{|c|}{0,93} & \multicolumn{2}{|c|}{0,296} & \multicolumn{2}{|c|}{0,445} & \multicolumn{2}{|c|}{0,420} \\
\hline t Stat & \multicolumn{2}{|c|}{$-0,263$} & \multicolumn{2}{|c|}{1,123} & \multicolumn{2}{|c|}{0,703} & \multicolumn{2}{|c|}{$-0,825$} \\
\hline $\mathbf{F}$ & \multicolumn{2}{|c|}{0,759} & \multicolumn{2}{|c|}{0,715} & \multicolumn{2}{|c|}{1,623} & \multicolumn{2}{|c|}{0,846} \\
\hline$\sigma_{\text {zaj }}$ & \multicolumn{2}{|c|}{12,749} & \multirow{2}{*}{\multicolumn{2}{|c|}{$\begin{array}{c}18,015 \\
\mathbf{- 0 . 2 8}\end{array}$}} & \multicolumn{2}{|c|}{13,08} & \multicolumn{2}{|c|}{11,25} \\
\hline g-Hedges & \multicolumn{2}{|c|}{0,02} & & & \multicolumn{2}{|c|}{$\begin{array}{l}-0,20 \\
\end{array}$} & \multicolumn{2}{|c|}{0,21} \\
\hline \multicolumn{9}{|c|}{ II class } \\
\hline Mean & 16,74 & 17,66 & 47,34 & 43,86 & 49,94 & 61,25 & 45,83 & 53,67 \\
\hline Variance & 149,35 & 271,43 & 145,97 & 364,27 & 142,39 & 216,69 & 147,07 & 186,49 \\
\hline Df & 30 & 30 & 30 & 30 & 30 & 30 & 30 & 30 \\
\hline $\begin{array}{l}\text { Std. Dev. } \\
\end{array}$ & 12,22 & 16,48 & 12,08 & 19,09 & 11,93 & 14,72 & 12,13 & 13,66 \\
\hline F-ratio Variances & \multicolumn{2}{|c|}{1,817} & \multicolumn{2}{|c|}{2,496} & & & & \\
\hline $\mathbf{P}$ & & & & & & & & \\
\hline t Stat & & & & & & & & \\
\hline $\mathbf{F}$ & & & & & & & & \\
\hline$\sigma_{\text {zaj }}$ & & & & & & & & \\
\hline g-Hedges & & & & & & & & \\
\hline & & & III C & & & & & \\
\hline Mean & 33,59 & 31,46 & 51,21 & 45,45 & 56,62 & 64,42 & 51,22 & 63,42 \\
\hline Variance & 257,83 & 191,42 & 185,02 & 169,71 & 134,43 & 228,13 & 248,67 & 348,86 \\
\hline Df & 33 & 33 & 33 & 33 & 33 & 33 & 33 & 33 \\
\hline Std. Dev. & 16,06 & 13,84 & 13,60 & 13,03 & 11,59 & 15,10 & 15,77 & 18,69 \\
\hline F-ratio Variances & & & & & & & & \\
\hline $\mathbf{P}$ & & & & & & & & \\
\hline t Stat & & & & & & & & \\
\hline $\mathbf{F}$ & & & & & & & & \\
\hline$\sigma_{\mathrm{zaj}}$ & & & & & & & & \\
\hline g-Hedges & & & & & & & & \\
\hline
\end{tabular}

Tab. 2. View of all results conducted in classes 


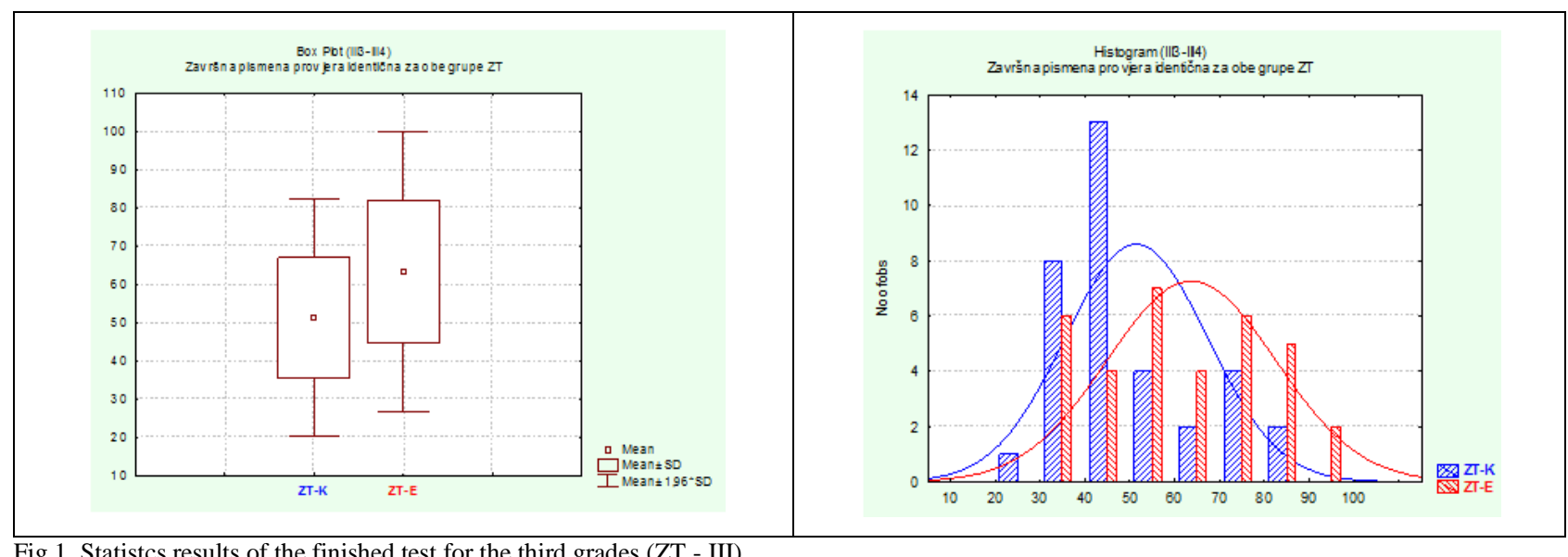

Fig 1. Statistcs results of the finished test for the third grades (ZT - III)

\subsection{Test results per classes}

According to all conducted tests in several classes and taken results, hypothesis $\mathrm{H} 1$ can be accepted, which was the aim of the research, i.e. to examine high school students' readiness to accept this teaching system.

\begin{tabular}{|c|c|c|c|c|c|c|}
\hline & I & $\begin{array}{c}\text { Statistically } \\
\text { sign diff. }\end{array}$ & II & $\begin{array}{c}\text { Statisticall } \\
\text { y sign diff. }\end{array}$ & III & $\begin{array}{c}\text { Statisticall } \\
\text { y sign diff. }\end{array}$ \\
\hline T1 & $-0,28$ & - & $-0,22$ & - & $-0,43$ & - \\
\hline T2 & $-0,20$ & - & 0,85 & + & 0,58 & + \\
\hline ZT & 0,21 & - & 0,61 & + & 0,71 & + \\
\hline $\begin{array}{c}\text { g (togeth.) } \\
\text { Hedges }\end{array}$ & $-0,09$ & $\begin{array}{c}\text { Unimportan } \\
\text { t effect size }\end{array}$ & 0,41 & $\begin{array}{c}\text { Middle } \\
\text { effect size }\end{array}$ & 0,29 & $\begin{array}{c}\text { Small } \\
\text { effect size }\end{array}$ \\
\hline $\begin{array}{c}\text { Hypothesi } \\
\text { s }\end{array}$ & \multicolumn{2}{|c|}{ Rejected } & \multicolumn{2}{|c|}{ Accepted } & \multicolumn{2}{|c|}{ Accepted } \\
\hline
\end{tabular}

Tab. 3. Statistical results per classes for all tests

We want to indicate that this is a short period of time for students to adapt completely to the new system. Teachers and pedagogues are being asked to pay attention to huge intercession in creating such courses, which in Bosnia and Herzegovina should be very common in all schools. That should create the strategy for the education sector development, with encouraging criterions for students and teachers, regarding the possibilities of the Internet use and concerning the obligations of Internet services presenter.

\section{CONCLUSION}

Results obtained in the survey cite the numerous opportunities of the blended learning implementation in secondary schools. This is based primarily on the fact that almost every household has IT technology, which opens the possibilities of full integration with traditional form of e-learning education. If this way of teaching is accessed systematically, it could increase the motivation of the students which is now at low level, primarily as the teaching does not change through decades, i.e. young people do not like it as it does not represent their interests in terms of achieving better results in learning. At this level, the system would be appropriate for the training curriculum, saving the talents for the competitions and helping students who slowly overcome curriculum.
Blended learning would achieve affirmation with the significant results if there is conducted the reform of the educational process, which would bind all the participants of educational process to use e-learning obligatory in all segments at a level that should be determined by experts in education.

The plan for the future research is to show how much influence blended learning has on the perception of the population of high school students and on the education over a longer period of time. And above all, the plan is to show which elements of blended learning are acceptable for students of this age in order to develop the best model of blended learning.

\section{REFERENCES}

[1] Gerlich, R. Nicholas, \& Sollosy, M. (2010). Comparing outcomes between a traditional F2F course and a blended itv course, Journal of Case Studies in Education

[2] Graham, C. R. (2005). Blended learning systems: Definition, current trends, and future directions. In Bonk, C. J.; Graham, C. R.. Handbook Of Blended Learning: Global Perspectives, Local Designs. San Francisco, CA: Pfeiffer., 3-21

[3] Linda J Mccown (2010). Blended courses: The best of online and traditional formats, 23(4), 205

[4] Ivankova, V. Nataliya (2010). Teaching and learning mixed methods research in computermediated environment: Educational gains and challenges, Copyright (C) eContent Management Pty Ltd. International Journal of Multiple Research Approaches 4: 49-65

[5] Nga-Sin Lau, Lui Lam \& Bo Zhou (2010). Enhancing blended courses to facilitate student achievement of learning outcomes, Proceeding ICHL'10 Proceedings of the Third international conference on Hybrid learning, Springer-Verlag Berlin, Heidelberg, ISBN:3-642-14656-2 978-3-642-14656-5

[6] Pamela A. H., Taurean T. D., Kerry W. F. \& William L. H. (2010). The impact of rich media presentations on a distributed learning environment engagement and satisfaction of undergraduate students, The Quarterly Review of Distance Education, 11(1), 53-58, ISSN 1528-3518

[7] Zemsky, R., \& Massy, W. F. (2004). Thwarted innovation, what happened to e-learning and why, University Of Pennsylvania, Weatherstation Project Of The Learning Alliance 